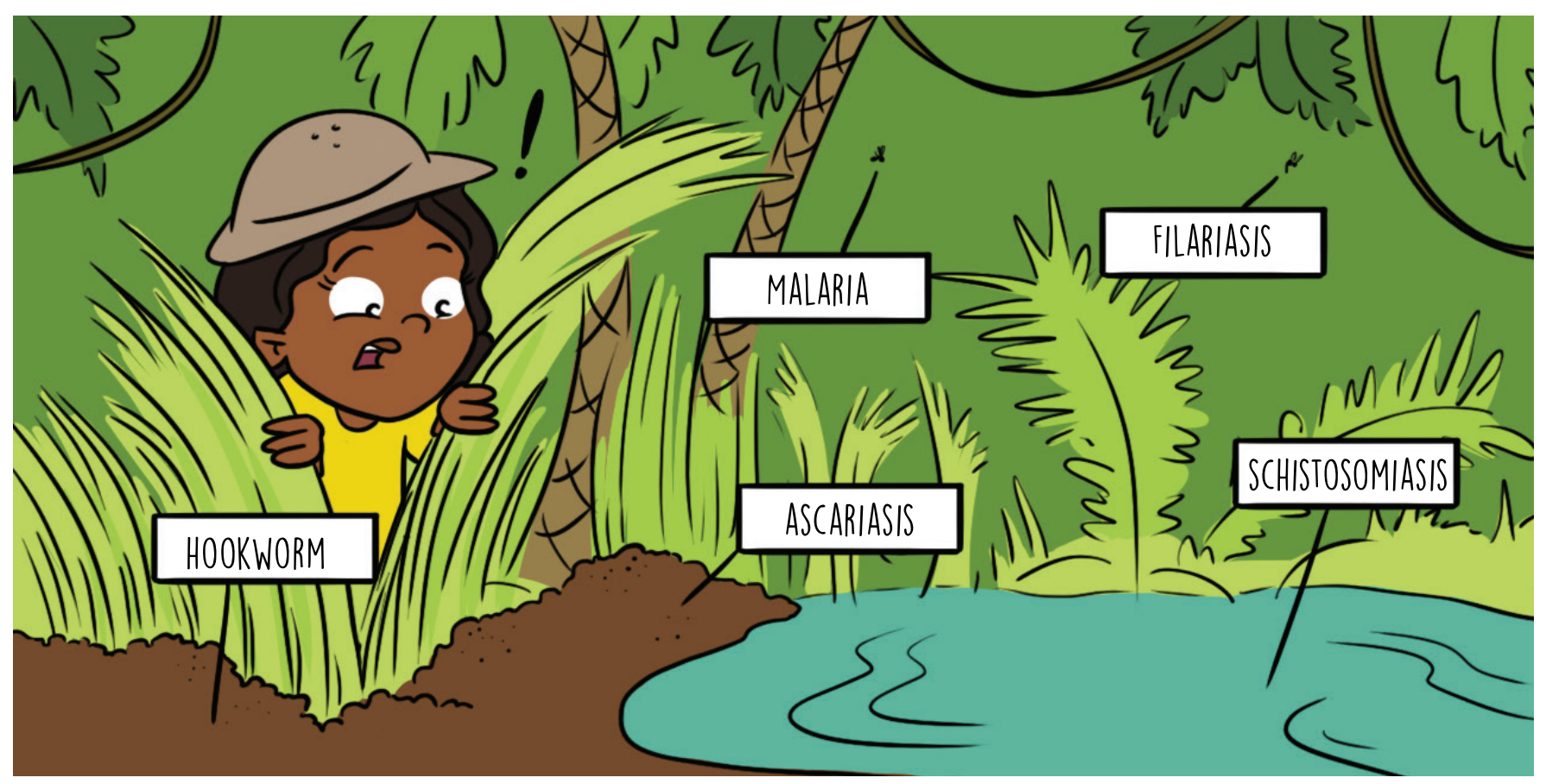

\title{
IMPORTANT HUMAN PARASITES OF THE TROPICS
}

\section{Binh Cao and Pascale S. Guiton*}

Department of Biological Sciences, California State University East Bay, Hayward, CA, United States

\section{YOUNG REVIEWER:}

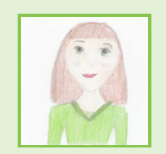

ANNA-MARIE

AGE: 13

\section{PARASITE}

A microorganism that lives in or on another organism from which it obtains nutrients and harms in the process.
All living things on this planet interact in one way or another with other living things. We use different terms to describe the interactions between two different species. If both species benefit from interacting with each other, that is, if each species relies on the other one for its well-being, then the relationship is called mutualism. In contrast, antagonism is the term used to describe a relationship that benefits only one of the species, while causing harm to the other one. In this article, we discuss a specific type of antagonism called parasitism. We will provide an overview of the diversity of parasitic species, discuss their role in major tropical diseases, and highlight the importance of the study of parasites to the medical field.

\section{WHAT IS A PARASITE?}

The word "parasite" will make most people cringe, probably because they associate it with little worms living inside them. This is not completely wrong, as we will see later. In the ancient Greek, however, the term "parasitos" was initially used to describe community officials who went 
Figure 1

Different groups of parasitic organisms. The asterisk (*) shows the groups of organisms that are considered parasites in the field of parasitology, which is the scientific study of parasites (These organisms are not drawn to scale).

\section{MICROORGANISM}

An organism that is too small to be seen with the naked eyes.

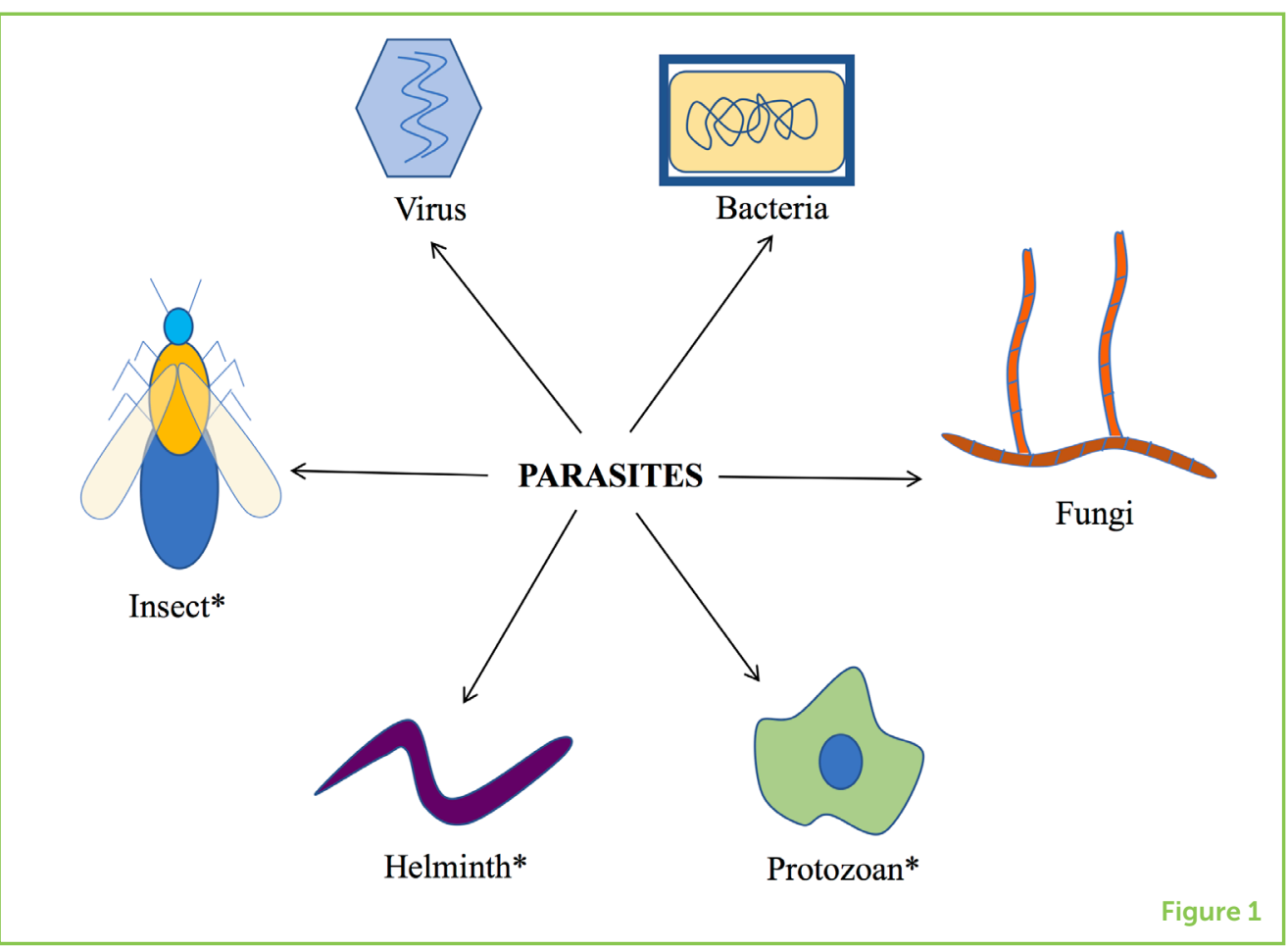

to public events and spent the community's money for their meals and entertainment [1]. Over time, "parasite" evolved to describe any person who lives off of other people's riches. It was not until the seventeenth century that the biologist Carolus Linnaeus used the term parasite to describe tapeworms. Nowadays, a parasite refers to any microorganism that is adapted to life in or on another organism, from which the parasite obtains nutrients while causing the other organism harm. This broad definition includes viruses and members of the six Kingdoms of life, namely Archaea, Bacteria, Fungi, Protozoa, Plantae, and Animalia (Figure 1). Yet, in parasitology, the field of biology that studies parasitic organisms, the term "parasite" applies only to protozoans (animals made up of a single cell), helminths (parasitic worms), and insects.

\section{PARASITES ARE VERY DIFFERENT FROM EACH OTHER}

Parasitologists (scientists who study parasites) study a very diverse group of organisms. In fact, the number of different species of parasites is so large that it is impossible to count all of them. Parasites can be divided into groups using many features, including their shapes and sizes, their geographical locations, the ways they move around, and the organisms they live in. Some parasites are made of only one cell (unicellular) and are as small as a few micrometers (one-thousandth of a meter). For instance, the banana-shaped Toxoplasma gondiiis about 6 micrometers long. In contrast, other parasites consist of multiple cells (multicellular) 
HOST

An organism that provides food and shelter for parasites.

\section{LYMPHATIC SYSTEM}

A system of vessels that drains lymph (fluid accumulated in tissues) into the circulatory system.

\section{DEFINITIVE HOST}

The host in which a parasite completes its sexual reproduction.

Figure 2

Ectoparasites vs. endoparasites. (A) Ectoparasites live outside and on the host. Examples include the cat flea Ctenocephalides felis, and can reach up to 80 feet $(25 \mathrm{~m})$ in length. An example of such parasite is the adult tapeworm.

Parasitic organisms are found almost everywhere, from tropical and sub-tropical regions to freezing places like Antarctica. Yet, what every parasite needs is an organism that provides food, shelter, and a place to reproduce. This organism is called a host. The host is eventually harmed by its interaction with the parasite. Parasites can be classified into two groups, depending on where they live in their hosts. Parasites that live outside the host are called ectoparasites (Figure 2A). For example, a flea is a parasite that lives on cats. In contrast, parasites that live inside their hosts are known as endoparasites (Figure 2B). For instance, Wuchereria bancrofti is a worm that lives in the human lymphatic system and causes a disease known as elephantiasis. Among the endoparasites, some can live inside the host cells and are called intracellular parasites. Plasmodium falciparum is one such parasite, because it lives and grows inside the red blood cells of people who have malaria.

Parasites also vary in the number of hosts they need to survive. While certain parasites need only one host, other parasites use multiple hosts to complete their life cycles. The host in which the parasite completes its sexual reproduction is called the definitive host.

\section{HOW DO PARASITES SURVIVE IN THEIR HOSTS?}

Parasitism is a constant battle for survival between the parasite and its host. Because parasites depend on their host for food and shelter, they must not destroy the host until they are ready to move on to the next host. Meanwhile, the hosts must protect themselves from harm. To protect themselves, the hosts constantly challenge parasitic organisms by creating unfavorable conditions. The host will try to deprive the parasites of nutrients, effectively starving them, or will attack the parasites with its strong immune defenses. To live in such a difficult environment, each parasite has evolved different survival strategies. Over millions of years of evolution, parasites have acquired lots of

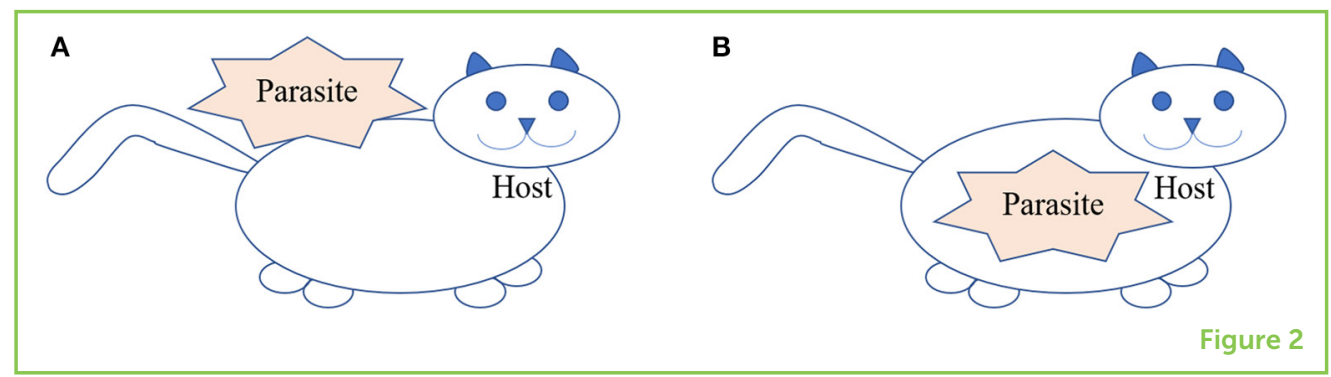


Figure 2

\section{Continued}

crab louse that lives on Human skin. (B)

Endoparasites live inside the host.

Examples include Dirofilaria immitis, a roundworm that lives inside cats and causes heartworm disease, hookworms inside human guts, and Plasmodium falciparum, a parasite that lives inside human red blood cells.

\section{HERMAPHRODITISM}

A reproductive strategy wherein female and male sexual organs are located on the same individual. interesting features to help them adapt to specific environments [1]. Here are some of them.

\section{Evading the host's attacks}

Each parasite is constantly challenged by the host's defenses and other unfavorable conditions, such as nutrient deprivation. Parasites have developed unique ways to respond to attacks by their hosts. For example, Trypanosoma brucei and P. falciparum, which cause diseases in humans, can change their appearances by switching the proteins on their surfaces and thereby avoiding recognition by the host's immune system. Other parasites have acquired the ability to directly kill human immune cells.

\section{Acquiring new reproductive strategies}

Parasites have evolved to live and reproduce within the environment of one particular host. This is called host specialization. While this strategy allows the parasite to be more successful inside that particular host, the host specialization also has its limitations, including reducing the parasite's chances of finding a mate. Parasitic organisms have evolved different ways to solve this problem. For Schistosoma species, once the female and male worms find each other in the host, they stick with each other forever, unless another male is present nearby. As for the tapeworms, they use a reproduction strategy called hermaphroditism. In hermaphroditism, both male and female reproductive organs are located on the same worm, which removes the need of finding a mate.

\section{Limiting damage to the host}

Another problem with host specialization is directly linked to the very nature of parasites. They damage their host. If the parasite is too destructive to its host, then the host may die before the parasite completes its life cycle. This can lead to the parasite's own death, or force the parasite to search for a new host. So, from the point of view of the parasites, it is important to limit the harm they cause, so that the host stays alive for a long period of time. Parasites have developed strategies to solve this problem. For instance, when there are lots of tapeworms present in a host, those worms will only grow to a small size, to avoid overwhelming and destroying the host. But each worm will grow larger when there are only a few worms present, because there is less competition for the host's resources and the host will not be so easily depleted. 


\section{HARMFUL EFFECTS OF TROPICAL PARASITES ON HUMAN HEALTH}

There are a number of parasites that cause diseases in humans. Parasitic diseases are most common in developing countries in tropical and sub-tropical regions of the world (Figure 3). These places are often hot and humid, conditions which are suitable for the growth of many parasites. In addition, tropical countries are often affected by poverty, poor sanitation, inadequate healthcare facilities, and low educational level. These factors often increase the transmission of parasitic diseases through insects, contaminated water, or contaminated soil, and make it difficult to control or eliminate them. Below, we describe some important parasitic diseases in tropical regions (Table 1).

\section{Malaria}

Malaria is one of the most common diseases in Africa and other tropical places, where it causes millions of deaths every year. P. falciparum is the protozoan responsible for this disease. The female Anopheles mosquito transmits the parasite when it draws blood from a human. $P$. falciparum infects red blood cells, which are then destroyed or changed in such a way that they clump together. These effects on the

Figure 3

Distribution of important parasitic diseases. The continents are shown in different colors. You can see the key in the upper right corner. The dots represent parasitic diseases. The key for the diseases is in the lower left corner. The size of the dots shows how common the disease is in the region/ continent-the larger the dot, the more people who are infected with the disease. You can easily see from this drawing that many parasitic diseases occur in tropical regions of the world (Not drawn to scale).

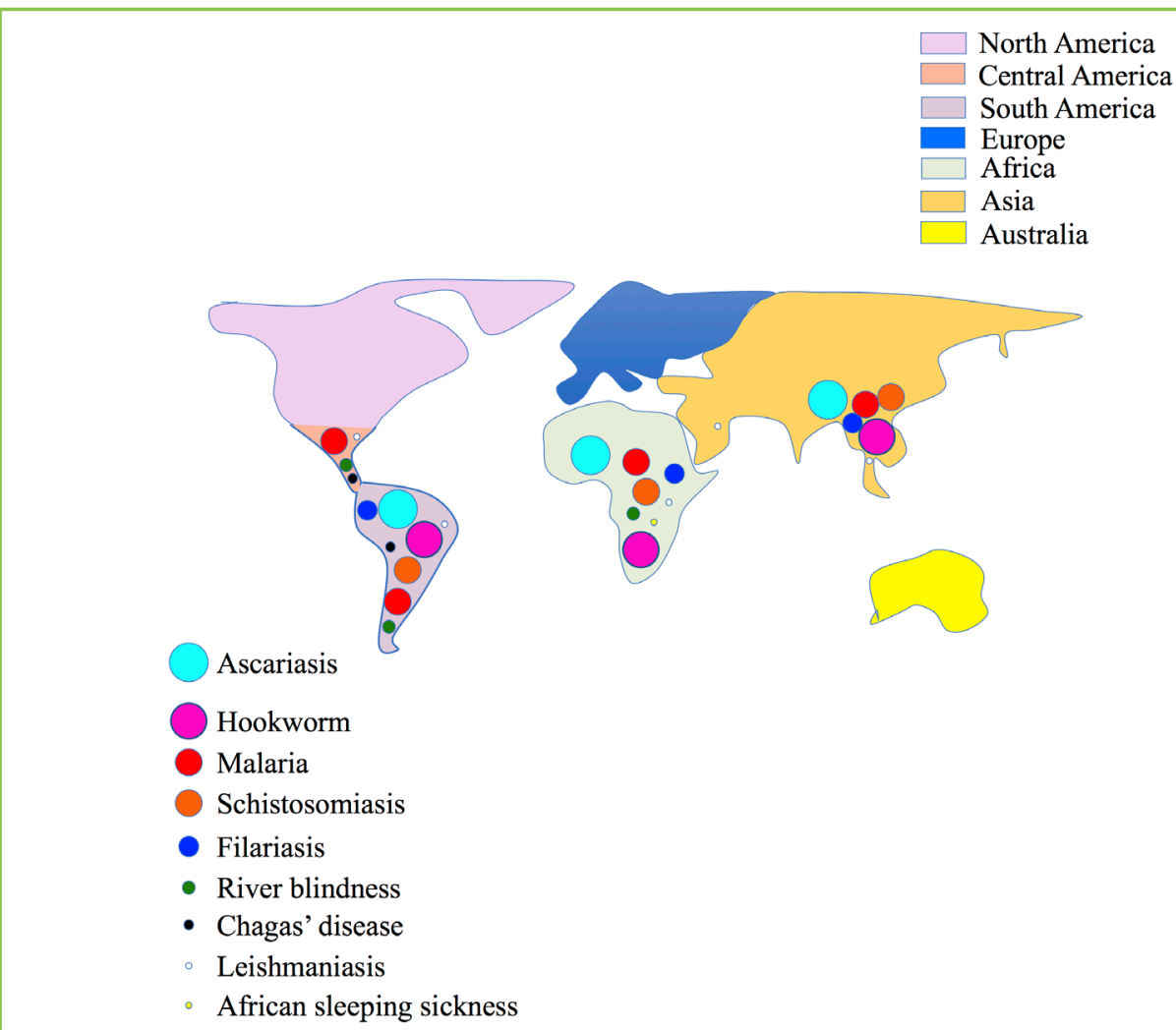

Figure 3 


\section{Table 1}

Summary of common tropical parasitic diseases.

*From the Center for Disease Control and Prevention at https:// www.cdc.gov/parasites.

**Number of new cases every year because of the acute nature of the disease.

\section{MACROPHAGE}

A type of white blood cell that kills pathogen by engulfing them, a process called phagocytosis.

\begin{tabular}{|c|c|c|c|}
\hline Disease name & $\begin{array}{l}\text { Frequency* (total } \\
\text { number of cases) }\end{array}$ & Parasitic organism & Transmission \\
\hline \multicolumn{4}{|c|}{ PROTOZOAL DISEASES } \\
\hline Malaria & $216,000,000$ & Plasmodium & Mosquito bites \\
\hline Leishmaniasis & $1,200,000$ & Leishmania & Sandfly bites \\
\hline $\begin{array}{l}\text { African sleeping } \\
\text { sickness }\end{array}$ & 10,000 ** & $\begin{array}{l}\text { Trypanosoma } \\
\text { brucei }\end{array}$ & Tsetse fly bites \\
\hline Chagas' disease & $8,000,000$ & Trypanosoma cruzi & Kissing bug feces \\
\hline \multicolumn{4}{|c|}{ PARASITIC WORM DISEASES } \\
\hline Schistosomiasis & $200,000,000$ & Schistosoma & Water \\
\hline Filariasis & $120,000,000$ & $\begin{array}{l}\text { Wuchereria } \\
\text { bancrofti }\end{array}$ & Mosquito bites \\
\hline River blindness & $25,000,000$ & $\begin{array}{l}\text { Onchocerca } \\
\text { volvulus }\end{array}$ & Blackflies bites \\
\hline Hookworm infection & $740,000,000$ & Necator americanus & Soil \\
\hline Ascariasis & $1,200,000,000$ & Ascaris lumbricoides & Soil \\
\hline
\end{tabular}

red blood cells result in poor blood supply to several organs and tissues, which can eventually lead to the death of the infected person.

\section{Leishmaniasis}

Leishmaniasis is transmitted to humans by female sandflies, which bite and release Leishmania organisms into the blood. Unlike P. falciparum, Leishmania prefers white blood cells, especially the ones called macrophages. Usually, the parasite causes a mild skin disease. However, it can sometimes invade and damage internal organs and cause more severe disease or even death.

\section{African Sleeping Sickness}

As its name suggests, African sleeping sickness is prevalent in Africa, where it affects around 10,000 people every year. It is caused by Trypanosoma brucei, a protozoan transmitted by the bite of tsetse flies. Infection with this parasite often leads to inflammation of blood vessels in multiple organs. Heart inflammation may ultimately lead to death from heart failure, or inflammation of the brain may cause seizures and excessive sleepiness. The sleepiness is why the disease is called "sleeping sickness".

\section{Chagas' Disease}

Chagas' disease is caused by another member of the trypanosomes, Trypanosoma cruzi. Unlike African sleeping sickness, Chagas' disease is 
more often seen in Latin America, where it currently affects eight million people. T. cruzi is released from the feces of the kissing bug, whose bite on the skin creates an entrance for the parasite into the bloodstream. The parasites spread throughout the body, damage different organs and cause inflammation of the heart and brain.

\section{Schistosomiasis}

Also called bilharziasis, schistosomiasis currently affects more than 200 million people in Africa, East Asia, and South America. Schistosomiasis is caused by flatworms called Schistosoma and is transmitted through water. The worm larvae in water penetrate the skin, enter the bloodstream, and finally take up residence in the intestines or the bladder. There, the worm larvae mature into adults and lay eggs, which activate the human immune system and cause persistent inflammation. Over time, the persistent immune activation may lead to cancer.

\section{Filariasis}

Usually called elephantiasis, filariasis is a disease that causes major body disfigurement. It is transmitted by mosquitoes and currently affects approximately 120 million people. The larvae of Wuchereria bancrofti, the roundworm responsible for this disease, are released into the bloodstream from a mosquito's bite. The larvae quickly migrate to the lymphatic system where they grow and mature into adults. When the roundworms get large, they prevent the flow of fluids through the tissues, so fluids accumulate in the tissue and cause grotesque swelling of the limbs and scrotum.

\section{River Blindness}

Caused by another roundworm, Onchocerca volvulus, river blindness currently affects 25 million people, mostly in Africa and South America. O. volvulus is transmitted by blackflies, which are insects that mainly live near and reproduce in rivers and streams. When introduced into the skin of a human, $O$. volvulus can stay there and mature. The presence of these worms in the skin triggers an immune response and causes skin inflammation. In other cases, the parasites migrate to the eyes, where they cause serious damage that leads to blindness. River blindness is a very common cause of blindness in tropical countries.

\section{Intestinal Infections With Roundworms}

Hookworms, such as Necator americanus, and ascarids, like Ascaris lumbricoides, are common roundworms in regions with poor sanitation. A. lumbricoides eggs are infective and can be ingested with foods 


\section{EOSINOPHIL}

A type of white blood cell that are recruited to fight helminths and play a role in allergies. containing contaminated soil, whereas hookworm eggs must hatch into larvae in the soil before they burrow through human skin. Both types of worms cause malnutrition, because they often live inside the gut where they compete with the host for nutrients. In severe cases, hookworms cause anemia, because they suck the blood of their hosts. Malnutrition and anemia in children can lead to problems with physical and mental development. Additionally, A. lumbricoides can also cause intestinal blockage, which results in intense abdominal pains in the infected person.

\section{ARE THERE HIDDEN BENEFITS OF PARASITIC INFECTIONS?}

By definition, parasites are harmful to their hosts. However, some parasitic infections may have protective effects against other diseases, such as allergies and chronic inflammatory bowel disease (IBD) [1]. Specifically, long-term infections with parasitic worms were shown to decrease allergies and symptoms of IBD. This is because parasitic worms have evolved strategies to block parts of the human immune system. These parts of the immune system, namely the eosinophils and IgE antibodies, are also the main players in allergies, IBD, and many other inflammatory diseases. So, maybe it is not surprising that people infected with parasitic worms have fewer allergies and inflammatory diseases! In fact, a study conducted in Africa and South America revealed that dewormed children (without parasitic infections) were more susceptible to allergies.

These recent findings inspired many scientists and doctors around the world to explore ways that parasitic infections may actually be helpful for some human conditions. The goal is to use these benefits to design new treatments for inflammatory diseases.

\section{CONCLUSION}

Parasites are a diverse and complex group of organisms that include the protozoans, helminths, and insects. Parasites have a complicated and constantly evolving relationship with their hosts, and that relationship is ultimately harmful to the host. Some parasitic organisms cause major diseases in humans, especially in tropical regions with conditions favorable to parasites' growth and transmission to hosts. Thanks to scientific advances, our understanding of parasitic organisms has expanded in recent years. Yet, the field of parasitology remains open and appealing to many. We have only scratched the tip of the iceberg. 


\section{REFERENCE}

1. Lucius, R., Loos-Frank, B., Lane, R. P., Poulin, R., Roberts, C., and Grencis, R. K. 2017. The Biology of Parasites. Weinheim: Wiley-VCH.

SUBMITTED: 23 June 2018; ACCEPTED: 04 October 2018;

PUBLISHED ONLINE: 29 October 2018.

EDITED BY: Ana Maria Rocha De Almeida, California State University, East Bay and University of California, Berkeley, United States

CITATION: Cao B and Guiton PS (2018) Important Human Parasites of the Tropics. Front. Young Minds 6:58. doi:10.3389/frym.2018.00058

CONFLICT OF INTEREST STATEMENT: The authors declare that the research was conducted in the absence of any commercial or financial relationships that could be construed as a potential conflict of interest.

COPYRIGHT () 2018 Cao and Guiton. This is an open-access article distributed under the terms of the Creative Commons Attribution License (CC BY). The use, distribution or reproduction in other forums is permitted, provided the original author(s) and the copyright owner(s) are credited and that the original publication in this journal is cited, in accordance with accepted academic practice. No use, distribution or reproduction is permitted which does not comply with these terms.

\section{YOUNG REVIEWER}

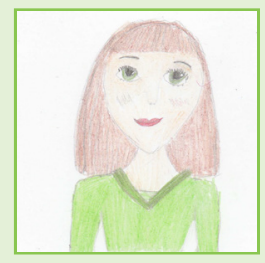

\section{ANNA-MARIE, AGE: 13}

I am very interested in finding new materials, because with more knowledge about it, the future could be changed. I also like the universe, because there is so much more than we know and think about in there to be found out. But the key to find out how the world works lays in the biology, because all starts with us humans and the evolution.

\section{AUTHORS}

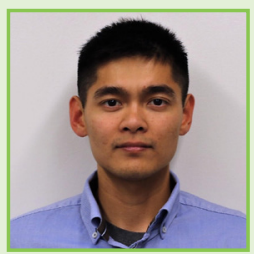

\section{BINH CAO}

I am a senior undergraduate student majoring in Microbiology at California State University East Bay in Hayward, CA. I interned at the National Institute of Allergy and Infectious Diseases in Bethesda, MD. My current research in Dr. Guiton's laboratory centers on understanding how proteins are trafficked to specialized secretory organelles in Toxoplasma gondii. I aspire to become a physician-scientist specializing in infectious diseases. 


\section{PASCALE S. GUITON}

I am very intrigued by the hidden world of microbes. I was trained as a molecular microbiologist at Washington University in St. Louis and Stanford University. The work in my laboratory seeks to understand the biology of the amazing parasite, Toxoplasma gondii. As a scientist-educator, I strive to teach my mentees the love of a work well done and instill in them the skills required for rigorous scientific experimentation. Besides playing with microbes, I love to hike with my family, play with my dog, and travel the world. *pascale.guiton@ csueastbay.edu 